\title{
Studies of Secretin-Stimulated Insulin Responses in Man
}

\author{
Roger L. Lerner and Daniel Porte, Jr. \\ From the University of Washington School of Medicine and Veterans \\ Administration Hospital, Seattle, Washington 98108
}

A B S T R A C T Recent studies have suggested that secretin, like glucose, stimulates a rapid insulin response from a small storage pool. In order to evaluate the mechanism of the secretin-stimulated insulin response, small (15 $\mathrm{U}$ ) rapidly administered intravenous injections (pulses) of secretin were given before, during, and after a $20 \mathrm{hr}$ $300 \mathrm{mg} / \mathrm{min}$ glucose infusion. Contrary to previous studies demonstrating that the acute insulin response to a small ( $5 \mathrm{~g}$ ) pulse of glucose given $45 \mathrm{~min}$ after the start of the glucose infusion was significantly diminished compared to the response to the preinfusion pulse, the acute insulin response (2-5 $\mathrm{min} \Delta$ immuno-reactive insulin $\mu \mathrm{U} / \mathrm{ml}$ ) to $15-\mathrm{U}$ secretin pulses exhibited a greater than twofold increase (before: $31.1 \pm 15.4$; during : $71.2 \pm 40.4$, $\mu \mathrm{U} / \mathrm{ml}$, mean $\pm \mathrm{sD}, P<0.02)$. The increased response to secretin was also found after $20 \mathrm{hr}$ of continuous glucose infusion, but was not observed $1 \mathrm{hr}$ after cessation of the infusion when plasma glucose levels returned to control values. Thus, this increased response to secretin was glucose dependent.

Four 150-U secretin pulses given at $30 \mathrm{~min}$ intervals elicited progressively and significantly diminished acute insulin responses with each succeeding pulse, consistent with depletion of the small storage pool. Similar to the observation that the magnitude of the insulin response to secretin was glucose dependent, the glucose-stimulated output appeared to be secretin dependent. Thus the acute insulin response to $5 \mathrm{~g}$ glucose was increased after secretin pretreatment (presecretin: $34.9 \pm 14.8$; postsecretin : $50.5 \pm 22.5 \mu \mathrm{U} / \mathrm{ml}, P<0.02)$ which suggests that

This work was presented in part at the National Meeting of the American Federation for Clinical Research, Atlantic City, N. J., May 1971.

Dr. Porte held Research Career Development Award 1K4 AM-8865. Dr. Lerner held National Institutes of Health Research Fellowship AM-40872 through June 1970 and was a Veterans Administration Research and Education Trainee through September 1971.

Dr. Lerner's present address is Department of Medicine, College of Physicians and Surgeons, Columbia University, New York 10032.

Received for publication 21 December 1971 and in revised form 20 March 1972. secretin may either enlarge the storage pool stimulated by glucose or increase its sensitivity.

The effect of epinephrine and propranolol on acute insulin responses to secretin and glucose was also different. $15-U$ secretin pulses were unaffected by infusions of either epinephrine (pre: $31.6 \pm 17.9$; during: $27.8 \pm 16.6$ $\mu \mathrm{U} / \mathrm{ml}$ ) or propranolol (pre: $12.8 \pm 8.4$; during : $10.7 \pm 5.5$ $\mu \mathrm{U} / \mathrm{ml}$ ). The results of these studies indicate that although both glucose and secretin stimulate a rapid insulin response, these responses are easily differentiated. The data suggest that glucose and secretin stimulate functionally separate storage pools of insulin, but that the acute response to either stimulus is partly determined by exposure to the other.

\section{INTRODUCTION}

Secretin stimulates insulin responses both in vitro and in vivo $(1,2)$. In contrast to glucose-stimulated insulin responses which have been shown to be both multiphasic and multicompartmental $(3,4)$, recent evidence suggests that secretin stimulates a characteristically uniphasic rapid insulin response derived from a small storage pool (5). The following studies were undertaken to evaluate further the mechanism of the secretin-stimulated insulin response.

\section{METHODS}

All subjects were between the ages of 21 and 29, were within $15 \%$ of ideal body weight according to the Metropolitan Life Insurance Tables, had no family history of diabetes mellitus, and were hospitalized for study on the Clinical Research Center of University Hospital. The basic protocol for the first study was previously published in detail for the glucose pulses (4), and therefore only a brief description follows. Six normal subjects received rapid intravenous injections (pulses, P) of $15 \mathrm{U}$ secretin $60 \mathrm{~min}$ before (P1) and $45 \mathrm{~min}$ after (P2) the onset of a 300 $\mathrm{mg} / \mathrm{min}$ glucose infusion. The infusion continued for approximately $20 \mathrm{hr}$ until the following morning, at which time another $15 \mathrm{U}$ secretin pulse (P3) was given. $1 \mathrm{hr}$ after the glucose infusion was discontinued the final $15 \mathrm{U}$ secretin pulse (P4) was administered. 


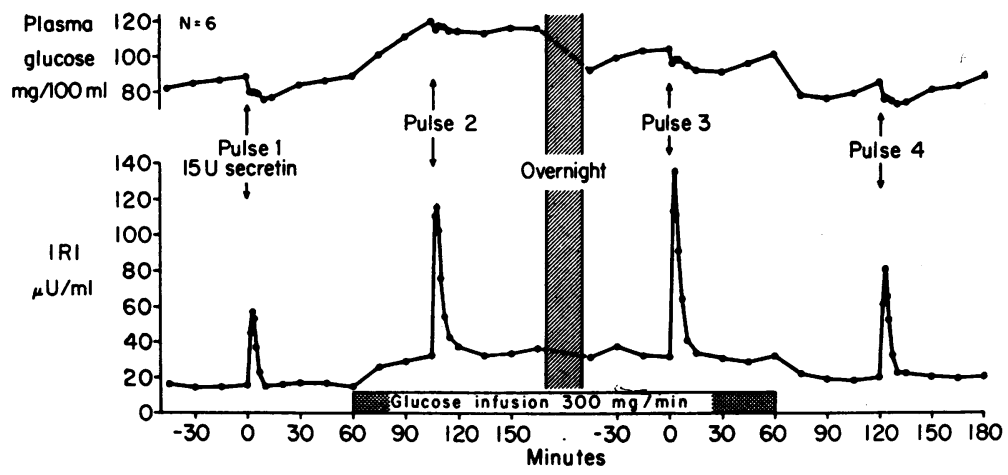

Figure 1 Mean glucose and insulin levels when 15-U secretin pulses were administered before, during, and after a $300 \mathrm{mg} / \mathrm{min}$ glucose infusion.

In the second study six normal subjects received a $5 \mathrm{~g}$ glucose pulse. $60 \mathrm{~min}$ later, a $150 \mathrm{U}$ secretin pulse was administered which was subsequently followed by three $150-\mathrm{U}$ pulses at $30 \mathrm{~min}$ intervals. $30 \mathrm{~min}$ after the final $150 \mathrm{U}$ secretin pulse, a second $5 \mathrm{~g}$ glucose pulse was given.

Five normal subjects comprising the third study received a $15 \mathrm{U}$ secretin pulse. $1 \mathrm{hr}$ later, a $6 \mu \mathrm{g} / \mathrm{min}$ epinephrine infusion was begun and continued for $120 \mathrm{~min}$. After the first $60 \mathrm{~min}$ of the epinephrine infusion, a second $15 \mathrm{U}$ secretin pulse was administered.

In the fourth study, six normal subjects received a 15 $\mathrm{U}$ secretin pulse. $30 \mathrm{~min}$ later propranolol administered as a $5 \mathrm{mg}$ pulse $+0.08 \mathrm{mg} / \mathrm{min}$ infusion was started. After 75 min of infusion, a second $15 \mathrm{U}$ secretin pulse was given and the infusion continued during the subsequent $30 \mathrm{~min}$.

In all studies the following procedures were employed. For multiple blood sampling a butterfly cannula was inserted in an antecubital vein; for infusing either epinephrine or propranolol, an identical cannula was inserted in the dorsum of the contralateral hand. All cannulas were maintained patent by a slow drip of $0.85 \% \mathrm{NaCl}$. Subjects receiving the overnight glucose infusion had a plastic catheter inserted under $1 \%$ lidocaine local anesthesia in the forearm vein of the opposite arm in which the sampling cannula was inserted. After insertion of all cannulas, a $60 \mathrm{~min}$ control period ensued, during which time four blood samples of glucose and insulin were obtained at $15 \mathrm{~min}$ intervals. An identical control period was observed on the 2nd day in subjects who received the long glucose infusion. After a secretin pulse, blood samples for glucose and insulin were obtained at $2,3,4,5,7,10,15$, and $30 \mathrm{~min}$; after a glucose pulse, blood samples for the same measurements were obtained at $3,4,5,7,10,15,30,45$, and $60 \mathrm{~min}$. After the start of the infusion of glucose, epinephrine, or propranolol, blood samples for glucose and insulin were obtained every $15 \mathrm{~min}$ for the duration of the infusion. After cessation of the long glucose infusion, four blood samples were obtained during the subsequent $60 \mathrm{~min}$ at $15-\mathrm{min}$ intervals.

The acute insulin response after a glucose pulse was estimated from the mean of the 3, 4, 5 min increment above either the mean of the four basal values or the last sample before a given pulse (3-5 $\left.\mathrm{min} \Delta \mathrm{IRI},{ }^{1} \mu \mathrm{U} / \mathrm{ml}\right)$. The acute insulin response to secretin was estimated from the mean of the 2, 3, 4, 5 min increments above either the mean of the four control samples or the value of the last sample before the pulse $(2-5 \mathrm{~min} \Delta \mathrm{IRI}, \mu \mathrm{U} / \mathrm{ml})$. The glucose

${ }^{1}$ Abbreviation used in this paper: IRI, immuno-reactive insulin.

TABLE I

Glucose and Insulin Values during Experiment 1

\begin{tabular}{|c|c|c|c|c|c|c|c|c|c|c|c|c|}
\hline \multirow[b]{2}{*}{ Subject } & \multicolumn{2}{|c|}{ Basal } & \multirow{2}{*}{$\begin{array}{l}\text { Pulse 1 } \\
2-5 \text { min } \\
\Delta \text { IRI }\end{array}$} & \multicolumn{2}{|c|}{$\begin{array}{l}45 \text { min glucose } \\
\text { infusion }\end{array}$} & \multirow{2}{*}{$\begin{array}{c}\text { Pulse } 2 \\
2-5 \text { min } \\
\Delta I R I\end{array}$} & \multicolumn{2}{|c|}{$\begin{array}{c}20 \mathrm{hr} \text { glucose } \\
\text { infusion }\end{array}$} & \multirow{2}{*}{$\begin{array}{c}\text { Pulse } 3 \\
2-5 \text { min } \\
\Delta I R I\end{array}$} & \multicolumn{2}{|c|}{$\begin{array}{l}60 \text { min post- } \\
\text { infusion }\end{array}$} & \multirow{2}{*}{$\begin{array}{c}\text { Pulse 4 } \\
2-5 \text { min } \\
\Delta I R I\end{array}$} \\
\hline & Glucose* & IRI* & & Glucose & IRI & & Glucose* & IRI & & Glucose & IRI & \\
\hline & $\mathrm{mg} / 100 \mathrm{ml}$ & $\mu U / m l$ & $\mu U / m l$ & $\mathrm{mg} / 100 \mathrm{ml}$ & $\mu U / m l$ & $\mu U / m l$ & $m g / 100 m l$ & $\mu U / m l$ & $\mu U / m l$ & $\mathrm{mg} / 100 \mathrm{ml}$ & $\mu U / m l$ & $\mu U / m l$ \\
\hline 1 & 94.3 & 23 & 53.3 & 139 & 77 & 106 & 109 & 48.3 & 91.2 & 100 & 24 & 43.3 \\
\hline 2 & 89.5 & 18.8 & 37 & 129 & 38 & 116 & 107 & 48 & 130 & 88 & 35 & 62.8 \\
\hline 3 & 104. & 19.3 & 22 & 141 & 20 & 59.5 & 119 & 32.3 & 69.7 & 93 & 20 & 32.5 \\
\hline 4 & 98.8 & 15.3 & 40.7 & 135 & 24 & 95 & 86 & 28.5 & 111 & 85 & 18 & 92.8 \\
\hline 5 & 95.8 & 7.3 & 11 & 131 & 14 & 21.3 & 112 & 11.5 & 29.5 & 81 & 9 & 20.3 \\
\hline 6 & 94.8 & 9.5 & 22.5 & 133 & 20 & 29.5 & 112 & 23.3 & 44.3 & 89 & 8 & 14.5 \\
\hline Mean & 96.1 & 15.5 & 31.1 & 135 & 32.2 & 71.2 & 107 & 32.0 & 79.3 & 89.3 & 19.0 & 44.4 \\
\hline SD & 4.9 & 6.1 & 15.4 & 45 & 23.4 & 40.4 & 11 & 14.3 & 38.8 & 6.6 & 10.0 & 29.3 \\
\hline
\end{tabular}

* Mean of four samples. 


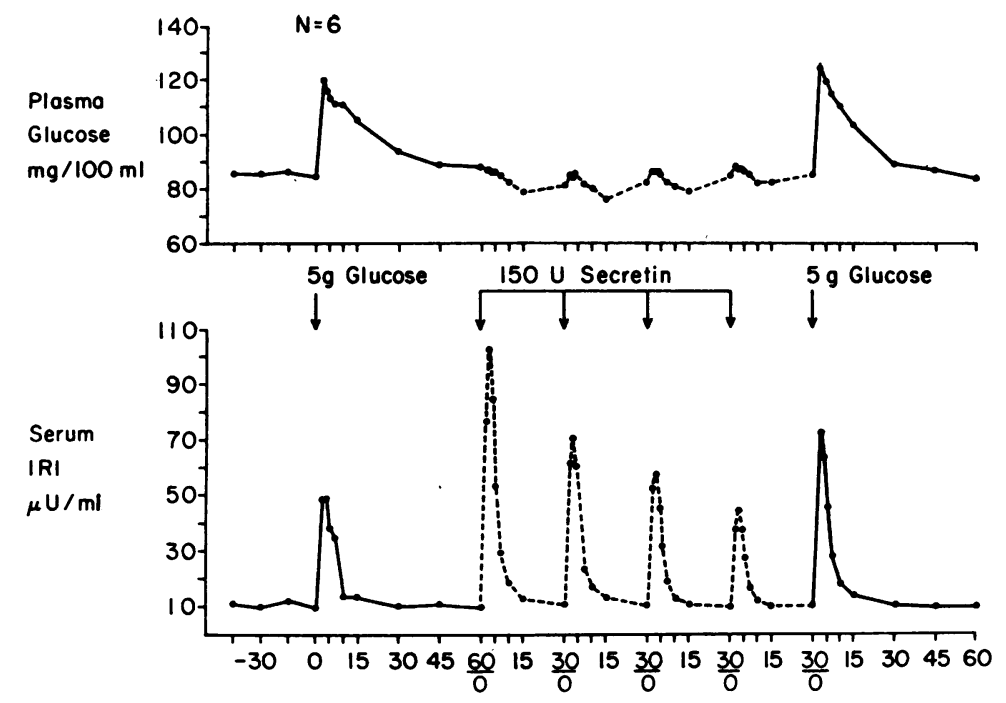

Figure 2 Mean glucose and insulin levels when $5 \mathrm{~g}$ glucose pulses were given before and after the administration of four $150-\mathrm{U}$ secretin pulses.

disappearance rate, $K_{G}$, was estimated from the decline in plasma glucose levels between 10 and $30 \mathrm{~min}$ calculated by the least squares technique (6). The blood samples for glucose and insulin were processed and measured as previously reported (4). Paired $t$ test was employed to assess the statistical significance of the data (7).

\section{RESULTS}

Insulin responses to secretin pulses before, during, and after a glucose infusion. All secretin pulses elicited rapid insulin responses which peaked within $5 \mathrm{~min}$ and were at prepulse values by 15 min (Fig. 1). The plasma glucose levels after all pulses declined, reaching a nadir within $15 \mathrm{~min}$ in all subjects (Fig. 1). After the onset of the $300 \mathrm{mg} / \mathrm{min}$ glucose infusion, elevation of both glucose $(P<0.05)$ and insulin $(P<0.01)$ levels were noted at $45 \mathrm{~min}$ (Table I). The acute insulin response to the second secretin pulse (P2) was associated with a greater than twofold elevation (Table I, $P<0.02$ ) compared to the preinfusion secretin pulse (P1).

After $20 \mathrm{hr}$ of glucose infusion, steady-state insulin levels were elevated in all subjects $(P<0.01)$ and steady-state glucose levels in five of the six subjects (Table I, $P<0.1$ ) compared to the respective basal levels of the 1st day. The third secretin pulse (P3) elicited an acute insulin response which was also greater than the response to secretin P1 (Table I, $P<0.02$ ), but was not significantly greater than the response to secretin P2 (Table I). After cessation of the infusion both glucose and insulin levels fell at or near preinfusion values of the 1st day (Table I). The final secretin pulse, $\mathrm{P} 4$, elicited a rapid insulin response which was not significantly increased compared to preinfusion control (P1) and was diminished compared to secretin pulses P2 $(P<0.05)$ and P3 $(P<0.01$, Table I $)$.

Insulin responses to 5-g glucose pulses before and after four 150-U secretin pulses. After the rapid intravenous injection of $5-\mathrm{g}$ glucose pulses, both the peak glucose and insulin levels occurred within 5 min (Fig. 2 ). The glucose disappearance rates in general paralleled the rapid insulin output to the glucose pulses (Table II). The acute insulin responses to the four $150-\mathrm{U}$ secretin pulses given at $30 \mathrm{~min}$ intervals progressively and significantly fell to each succeeding pulse (Table II, $P<0.05$ ). The subsequent 5 -g glucose pulse given $30 \mathrm{~min}$ after the final $150 \mathrm{U}$ secretin pulse was associated with increased acute insulin responses $(P$ $<0.02)$ and more rapid glucose disappearance rates (Table II, $P<0.05$ ).

Insulin responses to secretin pulses before and during epinephrine infusion. $60 \mathrm{~min}$ after the control secretin pulse, an epinephrine infusion was started. Plasma glucose levels promptly rose and by $60 \mathrm{~min}$ had reached a mean level of $170 \pm 31 \mathrm{mg} / 100 \mathrm{ml}$, (mean $\pm \mathrm{SD}, P$ $<0.01)$. No significant increase in basal insulin at $60 \mathrm{~min}$ of the infusion was observed (pre: 14.2 \pm 6.1 ; during: $19.8 \pm 11.7 \mu \mathrm{U} / \mathrm{ml}$ ). The acute insulin response was unchanged (Fig. 3) compared to preinfusion control (pre: $31.6 \pm 17.9$, during: $27.7 \pm 16.6 \mu \mathrm{U} / \mathrm{ml}$ ).

Insulin responses to secretin pulses before and during propranolol infusion. $30 \mathrm{~min}$ after the first secretin pulse insulin and glucose levels were essentially at prestimulated values (Fig. 4). Propranolol given as a 5 $\mathrm{mg}$ pulse $+0.08 \mathrm{mg} / \mathrm{min}$ infusion was begun and continued for the next $105 \mathrm{~min}$. During the first $75 \mathrm{~min}$ 
TABLE II

Glucose and Insulin Values during Experiment 2

\begin{tabular}{|c|c|c|c|c|c|c|c|c|c|c|c|c|}
\hline \multirow[b]{2}{*}{ Subject } & \multicolumn{2}{|c|}{ Basal } & \multicolumn{3}{|c|}{ Glucose pulse 1} & \multicolumn{4}{|c|}{$150-U$ Secretin pulses } & \multicolumn{3}{|c|}{ Glucose pulse 2} \\
\hline & Glucose* & IRI* & $\begin{array}{r}3-5 \min \Delta \\
\text { Glucose }\end{array}$ & $\begin{array}{c}3-5 \min \\
\Delta I R I\end{array}$ & $\mathbf{K}_{\mathbf{G}}$ & $\begin{array}{c}P 1 \\
2-5 \min \\
\Delta I R I\end{array}$ & $\begin{array}{c}\text { P2 } \\
2-5 \text { min } \\
\Delta I R I\end{array}$ & $\begin{array}{c}P 3 \\
2-5 \text { min } \\
\Delta I R I\end{array}$ & $\begin{array}{c}\text { P4 } \\
2-5 \text { min } \\
\Delta I R I\end{array}$ & $\begin{array}{r}3-5 \min \Delta \\
\text { Glucose }\end{array}$ & $\begin{array}{l}3-5 \min \\
\Delta I R I\end{array}$ & $\mathbf{K}_{\mathfrak{G}}$ \\
\hline & $m g / 100 m l$ & $\mu U / m l$ & $m g / 100 m l$ & $\mu U / m l$ & $\% / \min$ & $\mu U / m l$ & $\mu U / m l$ & $\mu U / m l$ & $\mu U / m l$ & $m g / 100 m l$ & $\mu U / m l$ & $\% / \min$ \\
\hline 1 & 91.8 & 14 & 32.2 & 29 & 1.70 & 44.5 & 45.3 & 28.5 & 30.3 & 39 & 44.3 & 2.44 \\
\hline 2 & 75.6 & 13.5 & 38 & 44.5 & 1.37 & 70 & 57.3 & 43.3 & 32 & 38 & 55.3 & 1.51 \\
\hline 3 & 93.3 & 8 & 24.7 & 9.3 & 1.70 & 54.8 & 38.5 & 32.3 & 15.8 & 30 & 20 & 1.84 \\
\hline 4 & 80 & 11.3 & 29 & 52.4 & 2.78 & 66.3 & 41.5 & 37.8 & 30.8 & 39 & 88.3 & 2.95 \\
\hline 5 & 90 & 8 & 30 & 35.7 & 1.33 & 49.8 & 36.8 & 31.8 & 23 & 31 & 41 & 2.12 \\
\hline 6 & 76.5 & 8.8 & 34.5 & 38.5 & 2.05 & 121 & 74.5 & 45 & 31 & 38 & 54 & 2.28 \\
\hline Mean & 84.5 & 10.6 & 31.4 & 34.9 & 1.82 & 67.7 & 48.9 & 36.5 & 27.2 & 35.8 & 50.5 & 2.28 \\
\hline SD & 8.0 & 2.7 & 4.6 & 14.8 & 0.54 & 27.8 & 14.5 & 6.7 & 6.4 & 4.2 & 22.5 & 0.56 \\
\hline
\end{tabular}

* Mean of four samples.

of the infusion, insulin levels declined $(-2.8 \pm 1.7 \mu \mathrm{U} /$ $\mathrm{ml}, P<0.02)$. The subsequent secretin pulse was associated with an unimpaired acute insulin response (pre: 12.8 \pm 8.4 ; during: $10.7 \pm 5.5 \mu \mathrm{U} / \mathrm{ml}$ ).

\section{DISCUSSION}

Since recent data indicate that both secretin and glucose stimulate rapid insulin responses from small storage pools $(4,5)$, it is pertinent to compare the patterns of responses during similar studies employing infusions of glucose (4), epinephrine (8), and propranolol (9). When the insulin responses to the small ( $15 \mathrm{U}$ ) secretin pulses are compared to those after a small $(5 \mathrm{~g})$ glucose pulse before, during, and after a glucose infusion as has been recently reported (4), important differences are readily noted. During the short glucose infusion, when a $5 \mathrm{~g}$ glucose pulse elicited a diminished acute insulin response compared to preinfusion control
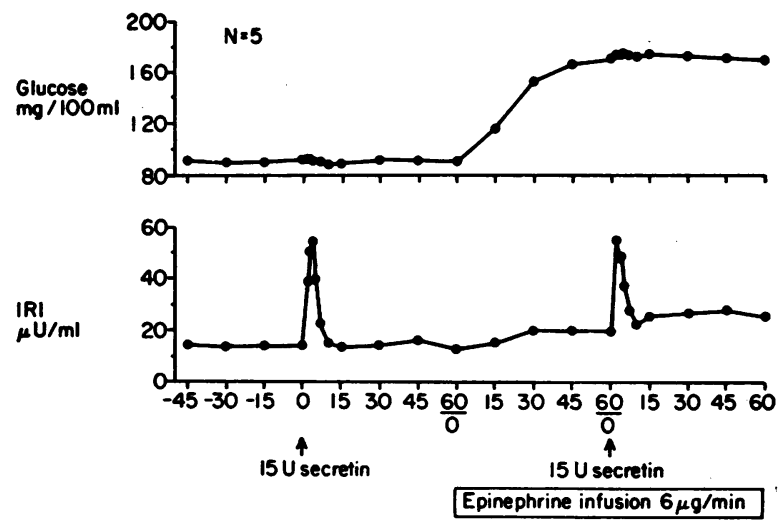

FIgURE 3 The effect of epinephrine on the insulin responses to secretin pulses.
( $-42 \%, P<0.001)$, secretin stimulates a greater than twofold increased rapid insulin response. After $20 \mathrm{hr}$ of glucose infusion the rapid insulin response to glucose is restored, but the duration of the total response is prolonged and appears similar to the biphasic response noted by Cerasi (10). In contrast, the insulin response to secretin pulse (P3) remains significantly greater than control (P1) but retains its uniphasic character (5). $1 \mathrm{hr}$ after cessation of the infusion, the acute insulin responses to glucose pulses are increased twofold $(P<0.001)$, but secretin-stimulated insulin responses are not greater than those elicited by the preinfusion pulse, P1. Furthermore, when four large (150 U) secretion pulses are given over a brief interval, the acute insulin responses progressively decreased; yet the subsequent $5 \mathrm{~g}$ glucose pulse elicited a $1 \frac{1}{2}$-fold increased insulin response.

Although the present and previous studies of secretin(5) and glucose- (4) stimulated insulin output are

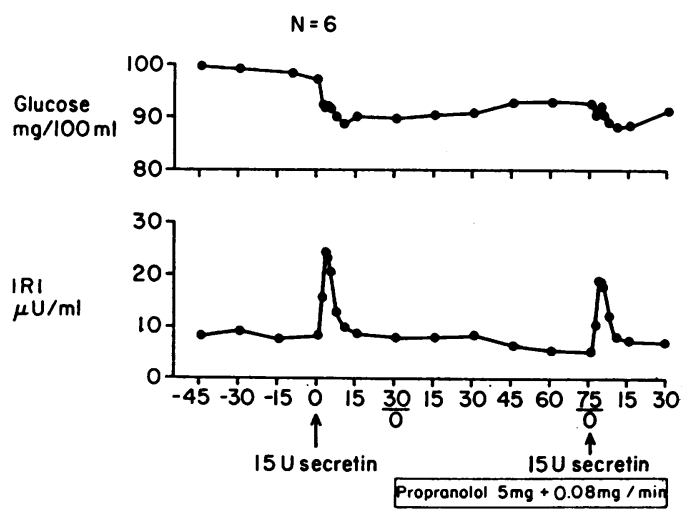

FIGURE 4 The effect of propranolol on the insulin responses to secretin pulses. 
consistent with the concept of stimulation of a small pool of readily available insulin, there was a complete dichotomy of acute insulin responses to glucose and secretin pulses during the same experimental conditions. Thus during studies in which a diminished acute insulin response to glucose is observed, the acute response to secretin is increased; and conversely, when a decreased acute insulin response to secretin is observed, the subsequent acute response to glucose is increased. In addition, when epinephrine and propranolol are infused at rates which are associated with blunted glucose-stimulated insulin responses $(8,9)$, the present data and that of others (11) indicate that the insulin responses to secretin are unimpaired.

What are the possible explanations for these observations? One possibility is that both glucose and secretin stimulate the same pool of readily available insulin but by different mechanisms. But how does this concept explain the paradox of a progressive fall of the rapid insulin responses to repetitive doses of secretin and an increased insulin response to the subsequent glucose pulse as observed in Experiment 2? One explanation is that repetitive stimulation alters the islet sensitivity to secretin which results in a decreased acute insulin response. The increased insulin response to the subsequent glucose pulse, which has been noted by others (12), may be another effect of secretin to make more insulin readily available to glucose stimulation, either by enlarging the size of the small storage pool or by increasing the islet sensitivity to glucose. The difficulty with this hypothesis is that it fails to explain the observations that a short glucose infusion which is associated with a decreased acute insulin response to a glucose pulse (4), is associated with an increased rapid insulin output to a secretin pulse as seen in Experiment 1 . The effect of a short glucose infusion appears to deplete the storage pool of insulin available for rapid release to a glucose pulse. Although it may be argued that this effect on the early response is related to altered islet sensitivity due to the presence of hyperglycemia, this would not explain the restored acute insulin response to the same glucose pulse when hyperglycemia is prolonged by continuing the infusion for $20 \mathrm{hr}$ (4). Thus if both glucose and secretin stimulate the same storage pool, a comparably diminished insulin response should have been observed to secretin in study 1 after 45 min of glucose infusion.

Therefore it seems that the one pool-separate mechanism hypothesis is insufficient to explain the results obtained and an alternative hypothesis may be considered: that glucose and secretin may stimulate separate functional storage pools of immediately releasable insulin. Such a hypothesis would explain the diminished insulin responses to both the multiple secretin pulses and during the short glucose infusion by postulating independent storage pools of insulin for glucose and secretin. The augmented rapid insulin response to secretin observed during the short or long glucose infusion suggests a transient enlargement of the storage pool available for secretin stimulation which is glucosedependent, since it is not present after the infusion is stopped; while the increased response to the second glucose pulse after four secretin pulses would suggest enlargement of the glucose-responsive pool which is secretin dependent. The lack of inhibition of the secretin-stimulated insulin responses during either epinephrine or propranolol infusion in contrast to that reported to glucose $(8,9)$ is consistent with a separate pool hypothesis.

Some other recent observations are compatible with separate pools. Hinz, Katsilambros, Schweitzer, Raptis, and Pfeiffer have noted that secretin either in the presence or absence of glucose did not stimulate insulin from isolated islets (13). Furthermore when rats had pancreatic exocrine insufficiency induced by ligation of the pancreatic and common bile ducts the rapid insulin responses to secretin were markedly diminished but the insulin responses and the glucose disappearance rates to intravenous glucose were indistinguishable from controls (14). Thus it appears that the integrity of the exocrine pancreas is essential for normal insulin responses to secretin. There are also preliminary observations in man to suggest that insulin responses to secretin are altered by exocrine pancreatic insufficiency $(15,16)$. Several investigators have reported that diabetic subjects appear to have almost normal rapid insulin responses to secretin despite markedly impaired insulin output after intravenous glucose (17-19). All of these data are compatible with the concept that glucose and secretin stimulate separate functional pools of insulin, the output from either pool being partly determined by the prior exposure of the islets to the other stimulus.

\section{ACKNOWLEDGMENTS}

This investigation was supported in part by U. S. Public Health Service Research Grant AM 12829, Training Grant AM 05498, and the National Institutes of Health Research Center facility of University Hospital (FR 37), Seattle, Washington.

The authors wish to acknowledge the excellent technical assistance of Mr. Howard Beiter.

\section{REFERENCES}

1. Pfeiffer, E. F., M. Telib, J. Ammon, F. Melani, and H. Ditschuneit. 1965. Direkte Stimulierung der Insulinsekretion in vitro durch Sekretin. Dtsch. Med. Wochenschr. $90: 1663$.

2. Dupre, J., L. Rojas, J. J. White, R. H. Unger, and J. C. Beck. 1966. Effects of secretin on insulin and 
glucagon in portal and peripheral blood in man. Lancet. $2: 26$.

3. Curry, D. L., L. L. Bennett, and G. M. Grodsky. 1968. The dynamics of insulin secretion by the isolated perfused rat pancreas. Endocrinology. 83: 572.

4. Porte, D., Jr., and A. A. Pupo. 1969. Insulin responses to glucose; evidence for a two pool system in man. $J$. Clin. Invest. 48: 2309.

5. Lerner, R. L., and D. Porte, Jr. 1970. Uniphasic insulin responses to secretin stimulation in man. J. Clin. Invest. 49: 2276.

6. Streeten, D. H., M. M. Gerstein, D. Woolfolk, and R. J. Doisy. 1964. Measurement of glucose disposal rates in normal and diabetic human subjects after repeated intravenous injections of glucose. J. Clin. Endocrinol. Metab. 24 : 761.

7. Snedecor, G. W., and W. G. Cochran. 1967. Statistical Methods. Iowa State University Press, Ames. 6th edition. 91 .

8. Lerner, R. L., and D. Porte, Jr. 1971. Epinephrine: selective inhibition of the acute insulin response to glucose. J. Clin. Invest. 50: 2453.

9. Cerasi, E., S. Effendic, and R. Luft. 1969. Role of adrenergeic receptors in glucose-induced insulin secretion in man. Lancet. 2 : 301.

10. Cerasi, E. 1967. An analog computer model for the insulin response to glucose infusion. Acta Endocrinol. 55 : 163.

11. Nelson, J. K., D. Rabinowitz, and T. J. Merimee. 1967. Effect of epinephrine on insulin release in man induced by secretin. Nature (Lond.). 215: 883.

12. Kraegen, E. W., D. J. Chisholm, J. D. Young, and L. Lazarus. 1970. The gastrointestinal stimulus to insulin release. II. A dual action of secretin. J. Clin. Invest. 49 : 524.
13. Hinz, M., N. Katsilambros, B. Schweitzer, S. Raptis, and E. F. Pfeiffer. 1971. The role of the exocrine pancreas in the stimulation of insulin secretion by intestinal hormones. I. The effect of pancreozymin, secretin, gastrin pentapeptide and of glucagon upon insulin secretion of isolated islets of rat pancreas. Diabetologia. 7: 1 .

14. Goberna, R., R. D. Fussganger, S. Raptis, M. Telib, and E. F. Pfeiffer. 1971. The role of exocrine pancreas in the stimulation of insulin secretion by intestinal hormones. II. Insulin responses to secretin and pancreozymin in experimentally-induced pancreatic exocrine insufficiency. Diabetologia. $7: 68$.

15. Rogers, J. B., J. M. Howard, and F. W. Pairent. 1970. Serum insulin levels in patients with chronic pancreatitis. Am. J. Surg. $119: 171$.

16. Raptis, S., R. M. Rau, K. E. Schroder, W. Hartmann, J. D. Faulhaber, P. H. Clodi, and E. F. Pfeiffer. 1971. The role of the exocrine pancrease in the stimulation of insulin secretion by intestinal hormones. III. Insulin responses to secretin and pancreozymin, and to oral and intravenous glucose, in patients suffering from chronic insufficiency of the exocrine pancreas. Diabetologia. 7: 160.

17. Deckert, T. 1968. Insulin secretion following administration of secretin in patients with diabetes mellitus. Acta Endocrinol. 59: 150.

18. Raptis, S., K. E. Schroder, and E. F. Pfeiffer. 1969. Insulin stimulating action of secretin in maturity onset diabetics. Horm. Metab. Res. 1: 91.

19. Lerner, R. L., and D. Porte, Jr., 1971. Secretin and glucose: stimulation of rapid insulin responses from separate storage pools. Clin. Res. 19: 478. (Abstr.) 